\title{
Numeral signs and compounding in Chinese Sign Language (CSL)
}

\author{
Junhui Yang
}

\section{Introduction}

Chinese Sign Language is a natural language in the visual-gestural modality used by the Deaf community in Mainland China. It is also used as an umbrella term to cover all signing systems, regional varieties, and manual alphabet (to fingerspell the sounds of Chinese characters) used by deaf people and hearing signers (Yang and Fischer 2002, Fischer and Gong 2012).

In the current Chinese political context, CSL is declared and documented by the China Disabled Persons' Foundation (CDPF) as the national Sign Language of China, and it is commonly used in teaching, media, and public places by deaf and hard of hearing people, and by other people who work with them or are related to them. CSL is often learned along with oral/ written Chinese Language in schools. There is an official publication entitled Chinese Sign Language (1987 edition, 1992 supplement, 2003 edition) which collects the signed forms of over 5000 Chinese words in common use in Beijing and Shanghai (representing the northern and the southern varieties). There is a volume of Basic Signs of Chinese Sign Language (2009), which has rearranged these signs according to the handshape and location order. This is used as a national standard (coded GB/T 24435-2009, project director Yu Lianjia).

Main dialectal varieties of CSL are usually identified by the city names: for example, Beijing, Tianjin, Shanghai, Yangzhou, Chongqing, Chengdu, and other large and middle-size cities where well-established deaf communities exist and where schools for the deaf have been established for more than 60 years (Fischer and Gong 2012).

In general, there are two regional varieties of CSL: the Northern regional variants (e.g., Beijing) and the Southern regional variants (e.g., Shanghai). In the west of China, their variants (except Tibet) are more similar or relevant to the South because there has been a great deal of deaf connection between the western and southern deaf communities in the past due to people travelling 
from Shanghai to the west via the Yangtze River. There is a remarkable mixing between the Northern and Southern regional varieties in the centre of China (near the Yellow River). The main difference between all regional varieties are at the lexical level. Lexical signs (e.g. names of objects, colour, number, and kinship terms) are created by local deaf people who use different signs to express the same meaning. The Northern regional varieties use more Chinese mouthing and borrowed signs based on Chinese word sounds and are influenced by Chinese word order, more so than the Southern regional varieties. The Southern varieties use more visually-motivated signs than the Northern varieties.

\section{The study}

This study aims to analyse and describe the phonological and morphological structure of number signs in CSL including cardinal and ordinal numbers, fractions, and numeral-incorporated forms. It is a part of the sign language typology project led by Zeshan and Sagara (2009-2013) based on questionnaires and research methodology guides. The eliciting materials used are the number questionnaire (Zeshan, DeVos and Sagara 2010), number games and animal pictures developed by the sign typology project team at iSLanDS, University of Central Lancashire.

Six deaf adults (30-50 years old) from Beijing (3) and Shanghai (3) voluntarily participated in this study. They were either deaf since birth or became deaf before the age of five. They attended schools for the deaf and began signing at an early age. The informants also were asked to provide a biographic narrative of their lives (topics including family and educational background, at what age they became deaf and began signing, jobs and travel). A total of 120 minutes of video recordings were collected.

\section{The phonological description of cardinal numeral signs in CSL}

\subsection{Handedness}

All signs of cardinal numbers in CSL are one-handed. Some regional variants use the non-dominant hands to support or clarify, for example, the non-dominant hand is used in signs for 70,80, 90 in the Shanghai variation. When expressing the year of 2001 to 2009, the non-dominant hand holds the number- 2 - handshape, while the dominant hand signs three other 
digits " 001 " or " 009 ". The use of two hands in numeral signs usually results in a morphologically complex sign, which is discussed further in the section on morphology below.

The signers from Shanghai sometimes sign for one hundred and hundreds in the double handed form, that is, the non-dominant hand simply copies the dominant hand, but this signing pattern does not change the meaning of the sign. If the second hand is dropped, the meaning of the hundred sign does not change. This Shanghai variation exemplifies the phonological level that one can use either use one hand or two hands to represent multiples of 100 from 100-900.

\subsection{Handshape and orientation}

The handshapes used to articulate cardinal numbers need to be precise but the orientation of the signs is less important and minor changes to this parameter do not affect the meaning of the numeral sign.

Simple numbers from 0 to 10 are identified by handshapes. The signs for 1-9 and 0 are one-handed and illustrated in fig 1.
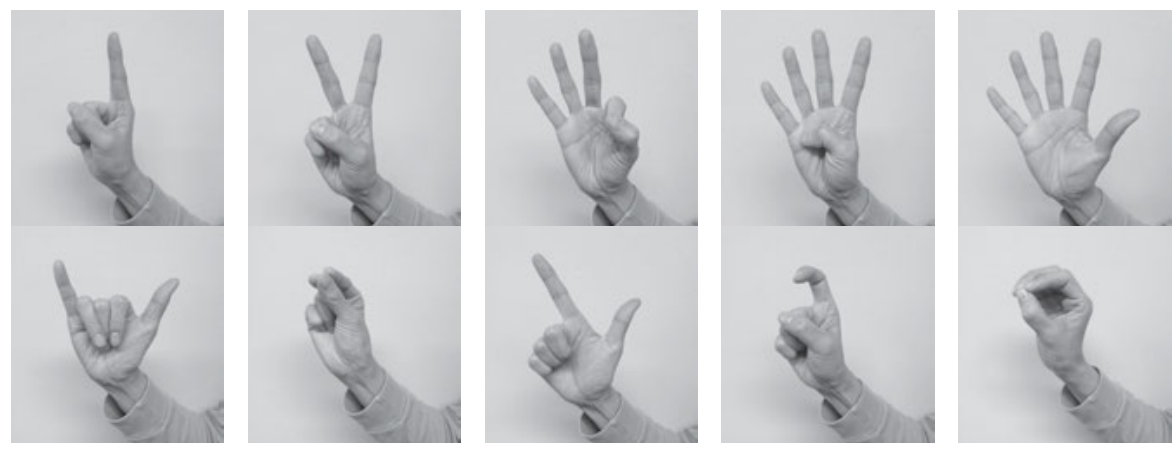

Figure 1. CSL numbers 1-9 and 0

In the signs 1 to 6 and 8 , extending fingers must be straight, and with the signs 0 and 9, fingers must be bent. In the articulation of the sign for 7 , fingers can either be straight or bent, and the sign 3 can be produced using either the $\mathrm{W}$ or $\mathrm{F}$ handshape. Both are dependent on the phonological context (other signs used before and after this sign, or units of measurement).

There are two variants of the sign TEN. In Beijing, signers cross the index and middle finger ( $R$ handshape, see figure 3a), but signers in Shanghai cross the thumb and index fingers (+ handshape). Both imitate the Chinese character + for ten in different ways. The Beijing variation for TEN can be 
compounded with the numbers $1-9$ to show teens, whereas the Shanghai variant for TEN is not possible to compound with other number signs to show teens and tens.

The editorial board of the Chinese Sign Language Dictionary decided to depict the TEN sign from Beijing for the dictionary and the number sign chart, and promoted this sign variant to be the common sign used nationwide. In the same dictionary, the Shanghai variant TEN is used for RED CROSS, additional mark in Mathematics, or as a passive mark "+", but not for TEN.

The handshape is the most important element in number signs to identify different numbers. There is no standard rule on the palm orientation as with Japanese Sign Language (Sagara 2013). The palm orientation of these signs $0-9$ is flexible and the meaning is the same with the palm towards or away from the signer. The direction of fingers can be either upwards or sideways. When they are used in ordinal numbers, the fingers pointing in a sideward angle (see figure 2) are more visibly indicative than the fingers pointing upwards (see figure 1).

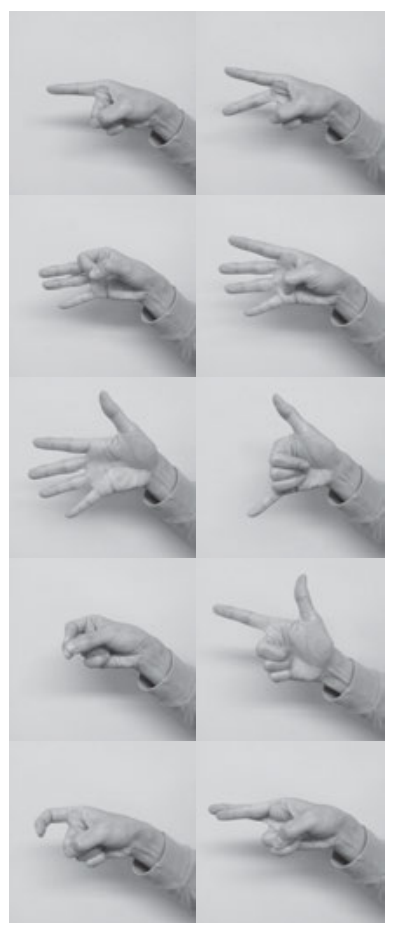

Figure 2. Basic numbers 
The sign $\mathrm{O}$ is always used in the middle of a multiple digit number, for example, 201, 1006, and at the beginning of a number less than 1 (e.g., 0.9, $0.85,0.5$ ). The sign 0 in the end of a number (e.g., the year of 1990, 2000, 2010) can be left out. For example, there is not a sign for 0 at the end in the signs for the numbers $210,350,4600$, or 180000 , because their last signs are TEN, FIFTY, SIX-HUNDRED, and EIGHT-THOUSAND, which are single signs without a gesture for 0 .

\subsection{Movement and location}

Numbers other than ten are a combination of two or more than two sequential number signs and are sometimes, modified with movement of the hand. For example, the sign for 100 is a one-handed sign that uses the index finger with a right-side movement.

The number system in CSL has characteristics of a 10-based system. When expressing the numbers of eleven and twelve all CSL signers produce signs like $\mathrm{TEN}^{\wedge} \mathrm{ONE}$ and $\mathrm{TEN}^{\wedge} \mathrm{TWO}$ in a sequential compounding format. There are two different variants for TEN in CSL; therefore, the signs for teens and tens are two different paradigms. In Beijing $(\mathrm{N})$, the signs for 11-19 sequentially combine two signs: the number TEN and a single number (1-9), for example, the handshape TEN (see Figure 3a) followed by the handshape SEVEN, becomes "SEVENTEEN"(see Figure 3c)

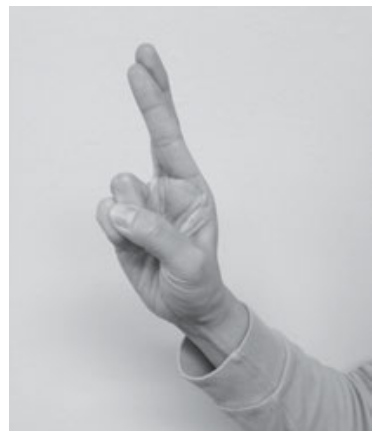

Figure $3 a$. TEN

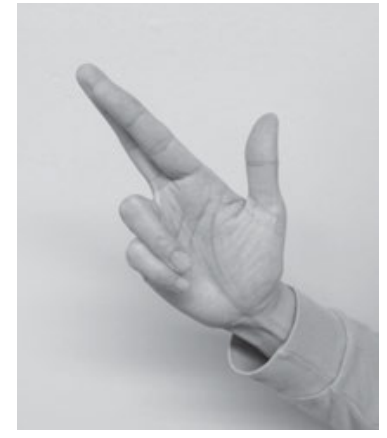

b. from 10 to 7 (in transition)

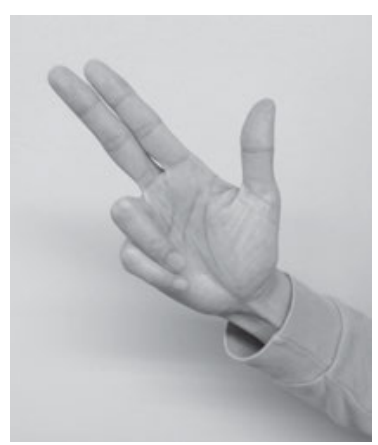

c. SEVEN

In Shanghai (S), individual digits may be used in a columnar format, resulting in a sequential compound, e.g., signing 1-3 to produce 13 . The sign for 11 consists of repeating the number 1 handshape while the hand moves from 
left to right, and 12-19 are two single numbers combined: the number 1 (represents TEN) and the number $2-9, \mathrm{ONE}^{\wedge} \mathrm{TWO} \ldots$ ONE^NINE. There is an alternative articulation for 11-19 where a movement (twisting) follows the number 1 hand and leads into the second numeral. The palm orientation of the two parts of the number sign is opposite.

There are lexical signs for the names of digits (unit), such as: hundred (bai 百), thousand (qian 千), and ten-thousand (wan 万), based on Chinese character shapes (strokes). The formational patterns of signs for hundreds, thousands and ten-thousands involve a numeral sign or handshape (a free morpheme) and a tracing movement (a bond morpheme) which is a modification after borrowing from the Chinese character. The following table 1 shows a summary of paradigms.

Table 1. Hundreds, Thousands and Ten-thousands paradigms

\begin{tabular}{lcll}
\hline Units & $\begin{array}{l}\text { Values } \\
\text { (numeral } \\
\text { handshape) }\end{array}$ & $\begin{array}{l}\text { Movement path (tracing } \\
\text { movement) }\end{array}$ & $\begin{array}{l}\text { Tracking part of } \\
\text { the character for } \\
\text { a unit }\end{array}$ \\
\hline Hundreds & $1-9$ & $\begin{array}{l}\text { Move right-sideward (Beijing); } \\
\text { Move forward (Shanghai) }\end{array}$ & $\begin{array}{l}\text { The first stroke } \\
\text { 'heng' “---"of the } \\
\text { character 百 }\end{array}$ \\
Thousands & $1-9$ & $\begin{array}{l}\text { Move to right and down } \\
\text { (completed movement); } \\
\text { Move down (uncompleted } \\
\text { movement) }\end{array}$ & $\begin{array}{l}\text { The whole } \\
\text { strokes of the } \\
\text { character 千; The } \\
\text { last stroke only }\end{array}$ \\
$\begin{array}{l}\text { Move to left down } \\
\text { Thousands }\end{array}$ & $1-9$ & $\begin{array}{l}\text { The second stroke } \\
\text { of the character 万 }\end{array}$ \\
\hline
\end{tabular}

\section{The morphological description of other numbers}

When expressing the multiples of ten, both Beijing and Shanghai variants use simultaneous compounding structures. Signing from twenty to ninety, the fingers of the number hands (2-9) are bent like hooks in the Beijing variance (this pattern is also found in Japanese Sign Language, Ktejik 2013), but in the Shanghai variance, the articulation of numbers is more phonologically complex: the fingers of the number hands $2-4$ and 7 in multiples of ten flip downwards; the numeral handshapes 5-9 close downwards to form a fist for 50 to 90 . The table 2 below shows a summary of morphological analysis of 10 to 99 . 
Table 2. Ten, Teens and Tens paradigms

\begin{tabular}{|c|c|c|c|c|}
\hline & $\begin{array}{l}\text { Number / } \\
\text { value }\end{array}$ & Beijing & Shanghai & $\begin{array}{l}\text { Morphological } \\
\text { structure }\end{array}$ \\
\hline Ten & 10 & $\mathrm{R}$ hand & + hand & One-handed \\
\hline Teens & $1-9$ & $\begin{array}{l}\{\mathrm{TEN}\}+\{\text { number }\} \\
\text { (The location and } \\
\text { palm orientation are } \\
\text { not changed ) }\end{array}$ & $\begin{array}{l}\{\mathrm{ONE}\}+\{\text { number }\} \\
\text { (The location or/ } \\
\text { and orientation are } \\
\text { changed }\end{array}$ & $\begin{array}{l}\text { Sequential } \\
\text { compound }\end{array}$ \\
\hline Tens & $2-9$ & $\begin{array}{l}\{\text { number }\} \# \\
\{\text { fingers bent }\} \\
=\{\text { TENS }\}\end{array}$ & $\begin{array}{l}\{\text { number\}\# } \\
\{\text { fingers flip down }\}\end{array}$ & Simultaneous \\
\hline $\begin{array}{l}21-29 \\
31-39 \\
\ldots \\
91-99\end{array}$ & & $\begin{array}{l}\{\mathrm{TENS}\}+\{\text { number }\} \\
\text { Different from the } \\
\text { teens }\end{array}$ & $\begin{array}{l}\{\text { number }\}+\{\text { number }\} \\
\text { The same as the } \\
\text { teens }\end{array}$ & $\begin{array}{l}\text { Sequential } \\
\text { compound }\end{array}$ \\
\hline
\end{tabular}

\subsection{The use of space showing fractions, ratio and date}

Fractions are indicated by a columnar difference, e.g. ONE produced above THREE for 'one-third'. In ASL the sign order is top-down, ONE is signed first then the hand moves down to show THREE. In CSL the sign order is bottom-up, THREE is signed first and then the hand moves up to show ONE (see the Figure 4). The non-dominant hand is used to form a horizontal bar to separate the two number sign spaces in the fraction paradigm.
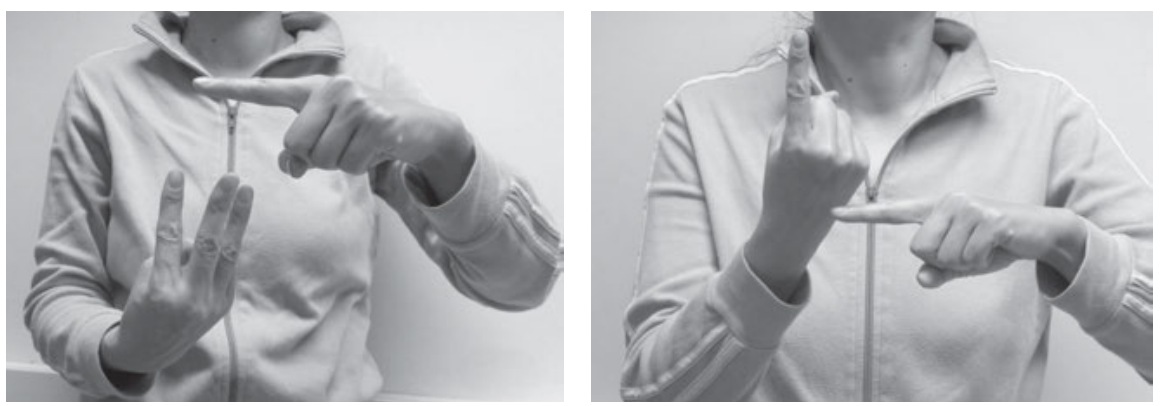

Figure 4. Two-handed sign showing one third (1/3)

There are two signs meaning "percentage": the index finger drawing a "/" mark and tracing the symbol "\%" in the air to show the unit "percentage'. The percentage sign " $\%$ " is then followed by a number sign to indicate what percentage the signer is talking about. 
In the ratio and score paradigms, two hands show numbers at the same time to display the ratio (scores) between two parties. Two hands are fingervertical and in different locations related to possession (e.g., my score or my team's score vs. your score or your team's score):

(1) one hand is on the left side and the second hand is on the right side to show two opposite groups' scores;

(2) one hand is inward to show my group's score and the second hand is outward to show your group group's score ,

(3) one hand is inward in which the syntactical space represents the first person, on my side's score, and the second hand is located on the other side, in which the syntactical space represents the third party.

In the date paradigm two hands are finger-horizontally arranged: one hand is up and the second hand is underneath. The number hand on the top represents the month (e.g., May); the second number hand on the bottom represents which day of the month (the third day of May).

\subsection{Other morphological paradigms}

The cardinal number signs occurring in high frequencies are one to the ten. All ordinal numbers are bi-morphemic and two-handed signs, with each hand representing a morpheme:

\{Free morpheme: number\} \{Bound morpheme: semantic unit\}

The dominant hand with a number handshape touches on the non-dominant hand, either on the thumb (the Beijing variance) or the back of hand (the Shanghai variance). The ordinal numbers in CSL are fully productive, and any ordinal number can be expressed. The bound morpheme for the order mark (e.g., the number hand touching on the non-dominant hand) can sometimes be omitted. If they are translated into Chinese, a morpheme for the numerical order "Di " (similar to the morpheme $\sim$ th in English) needs to be added. Sometimes ordinal numbers are formed by pointing at the fingers of the non-dominant hand when giving a list or explaining items point by point.

When numbers combine with a semantic unit (e.g., months of the year, days of the week, school names, grade levels, floors of a building), the number sign touches on a specific location (e.g., a part of the signer's body or the non-dominant hand). The following Table 3 shows some details. 
Table 3. Time, Age, Ordinal, Size and Money paradigms

\begin{tabular}{|c|c|c|c|}
\hline Paradigms & $\begin{array}{c}\text { Value } \\
\text { (number } \\
\text { handshape) }\end{array}$ & $\begin{array}{l}\text { Semantic unit (Beijing } \\
\text { variation) }\end{array}$ & $\begin{array}{l}\text { Semantic unit (Shanghai } \\
\text { variation) }\end{array}$ \\
\hline months of year & $1-12$ & $\begin{array}{l}\text { on the index finger of } \\
\text { the non-dominant hand }\end{array}$ & Marking a moon shape \\
\hline $\begin{array}{l}\text { days of the } \\
\text { week }\end{array}$ & $1-7$ & $\begin{array}{l}\text { on the palm of the non- } \\
\text { dominant hand }\end{array}$ & $\begin{array}{l}\text { Taking the number hand } \\
\text { out of the armpit }\end{array}$ \\
\hline Age & $1-99$ & $\begin{array}{l}\text { on the back of the non- } \\
\text { dominant hand (fist) }\end{array}$ & On the palms \\
\hline Years & $1-99$ & $\begin{array}{l}\text { On the non-dominant } \\
\text { hand (fist) }\end{array}$ & On the palms \\
\hline Months & $1-12$ & Making a moon shape & $\begin{array}{l}\text { On the index finger of } \\
\text { the non-dominant hand }\end{array}$ \\
\hline Weeks & $1-4$ & On the number 7 hand & Brushing over the nose \\
\hline Days & $\begin{array}{c}1-10,20 \\
30,40 \ldots 90\end{array}$ & On the top of the head & On the side of the head \\
\hline O'clock & $1-12$ & $\begin{array}{l}\text { On the wrist of the non- } \\
\text { dominant hand }\end{array}$ & $\begin{array}{l}\text { On the wrist of the non- } \\
\text { dominant hand }\end{array}$ \\
\hline Hours & $1-12$ & $\begin{array}{l}\text { On the wrist of the non- } \\
\text { dominant hand }\end{array}$ & $\begin{array}{l}\text { On the palm of the non- } \\
\text { dominant hand }\end{array}$ \\
\hline $\begin{array}{l}\text { Deaf School } \\
\text { sign names }\end{array}$ & $1-4$ & $\begin{array}{l}\text { brushing from ear to } \\
\text { mouth }\end{array}$ & On the shoulder \\
\hline grade levels & $1-9$ & on the chin & In front of the signer \\
\hline row (seats) & $1-90$ & $\begin{array}{l}\text { on the index finger side } \\
\text { of the } \mathrm{B} \text { hand }\end{array}$ & \\
\hline places in a line & $1-10$ & on the chin & $\begin{array}{l}\text { On the back of the non- } \\
\text { dominant hand (fist) }\end{array}$ \\
\hline People & $1-10$ & $\begin{array}{l}\text { On the index fingertip of } \\
\text { the non-dominant hand }\end{array}$ & $\begin{array}{l}\text { On the index fingertip of } \\
\text { the non-dominant hand }\end{array}$ \\
\hline Size (HAO) & $\begin{array}{c}1-10,20 \\
30,40 \ldots 90\end{array}$ & $\begin{array}{l}\text { On the corner of the } \\
\text { mouth }\end{array}$ & Circle around the lips \\
\hline $\begin{array}{l}\text { Seconds FEN } \\
\text { / money JIAO } \\
\text { ( } 1 / 10 \text { yuan })\end{array}$ & $1-60$ & $\begin{array}{l}\text { On the chin and twisting } \\
\text { the wrist }\end{array}$ & $\begin{array}{l}\text { On the non-dominant } \\
\text { hand (O handshape) }\end{array}$ \\
\hline CN Yuan (RMB) & $1-10$ & In front of the signer & Under the chin \\
\hline
\end{tabular}


Signs belonging to some paradigms (e.g., size, time, age, row, person, deaf school sign names) have originated as a base lexical sign then, over a period of time, a numeral sign has been incorporated sequentially and, eventually, the two elements have become articulated together, resulting in simultaneous compounding. They can go through the three steps of morphological process, and their two morphemes can be separated and compounded. Some other paradigms do not have the base lexical signs, for example, 'week' or 'month', but use 'one-week' or 'one-month' to express the same concept of 'week' or 'month'. Similar patterns are described in Zeshan's study of IndoPakistan Sign Language (Zeshan 2000). These lexical signs are used with number incorporation; their morphemes have to be compounded simultaneously and cannot be separated into two individual signs.

Two-handed number signs (e.g. in the 'date' paradigm and the 'ratio' paradigm) do not have any base signs. For example, two-handed number 1 signs for January $1^{\text {st }}$ or 1:1 cannot be used to express the general concept of "date" or "ratio", but rather they depict one specific date or ratio. When using number incorporation with two hands the location of each hand is important because the individual location becomes a morpheme that represents a unit of measurement, semantic unit or a pronoun.

\section{Syntactic description of number signs and quantity markers}

There are strategies for marking nominal plurals and analysis of the data indicates that such strategies exist with regular frequency. Number signs may be marked for an exact amount or for an unspecified quantity. The strategies available in CSL include the following:

1. Combining a nominal sign with a cardinal number. The number signs are shown either before the nouns (for a long sentence) or after the nouns (for a short sentence). If the noun is the sentence topic, the number sign is a comment to depict the quantity of the objects. The nominal sign often does not repeat if it is shown before the number sign. For example,

BIRD FIVE

'Five birds'

CAT THREE

'Three cats'

THREE CAT ONE BIG (shoulder shift) TWO SMALL SMALL

'There are three cats; one is large, and the other two are small'. 
2. Repeating a nominal sign in a following or connected clause and pointing in different areas in the signing space ( 2 or 3 ). This is illustrated by the example:

CAT ONE MOTHER (pointing-to-the-left) CAT TWO CHILDREN (pointing to the right) 'One cat is the mother, and the other two are her kittens'.

3. Repetition/reduplication of the lexical sign indicates plurality. It usually repeats twice and the location of the hands is slightly changed as a result of the sideward movement. For example, TREE+, CHAIR+.

4. Repetition of an entity classifier with some spatial modifications. Individually articulated repetitions of the classifier at different locations in the signing space (e.g., flowers). Sometimes a definite number is given before the classifier predicate. The repetition will be as exact as the given numbers $(2-5)$. For example,

Rh: ROPE (CL:R) FIVE BIRD CL:Y CL:Y CL:Y CL:Y CL:Y

Lh: ROPE (CL:R)

$(\mathrm{CL}: \mathrm{R})$

'There are five birds on a long rope".

5. Using indefinite number signs, for example, A FEW / SEVERAL/ SOME, that is the one-handed open-5 finger-wiggling without interrogation facial expression (see figure 5). The one-handed sign MANY does not require the wiggling of fingers but is defined by the flicking of the wrist. The double-handed sign MANY can often be used to show the extent of something, as the use of two hands adds extra quantification. Facial expressions and the sideward movement of the hand (i.e. larger use of the signing space) are adjective functions thus giving emphasis and increasing the degree of quantity even further.

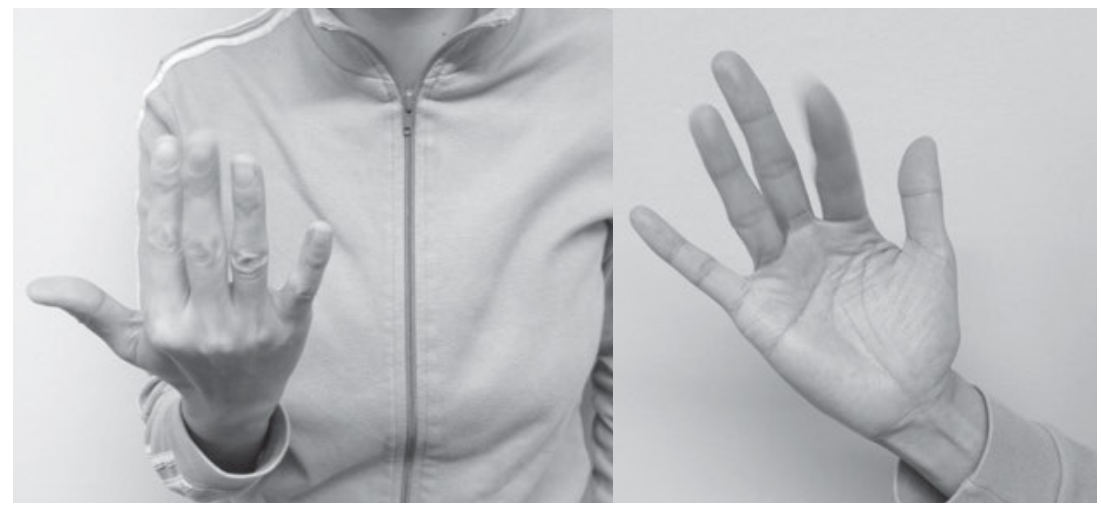

Figure 5. The one-handed open-5 finger-wiggling without interrogation facial expression 
6. There are suppletive plural forms, e.g. PERSON vs. PEOPLE; YOU vs. ALL-OF-YOU, where the additional sweeping movement of the original sign represents a plural morpheme. Pluralisation in this instance is not accompanied by a descriptive adjective to indicate there are MANY or LOTS of people - the sweeping movement is an independent indicator of lexical plurality, serving as a plural morpheme.

Distinguishing general quantifiers from "none" or "several" to "all/whole"

There are some quantifiers that are used to make generic statements, from none, or a little to all. For instance: NONE /NOTHING/ HAVE-NOT is produced by the one-handed $\mathrm{O}$ handshape placed in front of the signer or on the mouth of the signer; ONE TWO 'one or two' is extended the index finger and the middle finger one by one; TWO THREE 'two or three' is sequentially combined the number sign 2 and 3; A LITTLE / A FEW is produced by the thumb touching on the tip of the index finger and then moving up.

There is a one-handed sign for HALF in CSL (see figure 6) which begins with the placement of the thumb half way down the extended index finger (at the second knuckle), forming a similar handshape to the + sign in CSL. The thumb is moving in a downwards motion, and this motion can be singular or repeated without changing its meaning. The HALF sign is often combined with the number signs in the age, time, year, weight and other units of measurement paradigms. For example, in CSL, if signing about someone's age HALF YEAR-OLD or time of day HALF DAY, the thumb is drawn down once over the second knuckle of the index finger to represent the 'half' element.

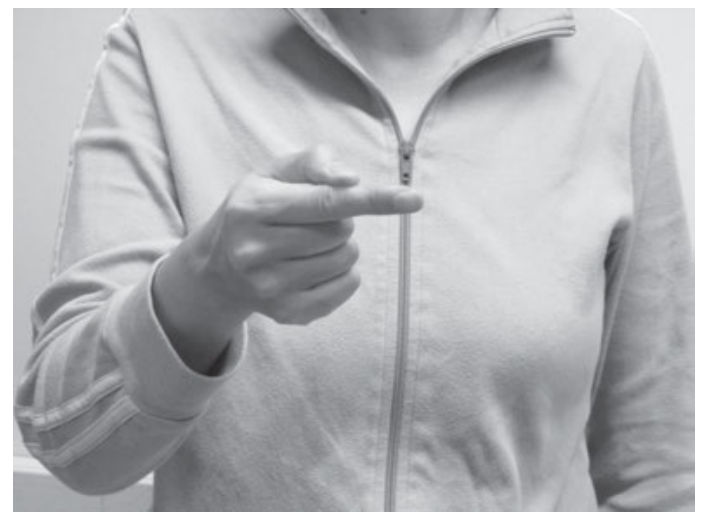

Figure 6. HALF 
Alternatively, denoting "some parts" in CSL, the thumb can be repeatedly flicked downwards over the second knuckle of the index finger, SOME PEOPLE COME, SOME PEOPLE GO 'some people came and some people left'.

Other quantifiers indicate an amount that is more than half. For the following signs, the use of two hands may be stylistic or may be used to add extra meaning:

MANY (one-handed, figure 7)

MANY (two-handed, figure 8)

VERY MUCH/MANY (one-handed)

VERY MUCH/MANY (two-handed)

ALL /WHOLE (two-handed)

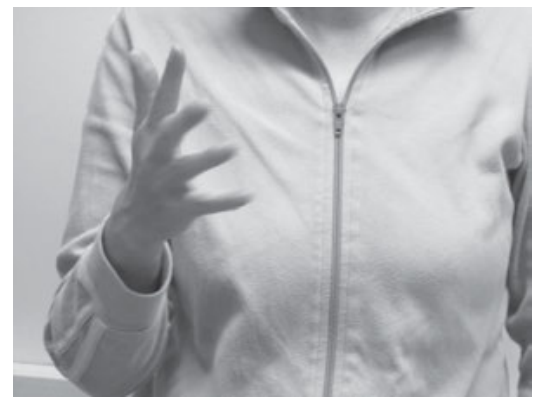

Figure 7. MANY (one-handed)

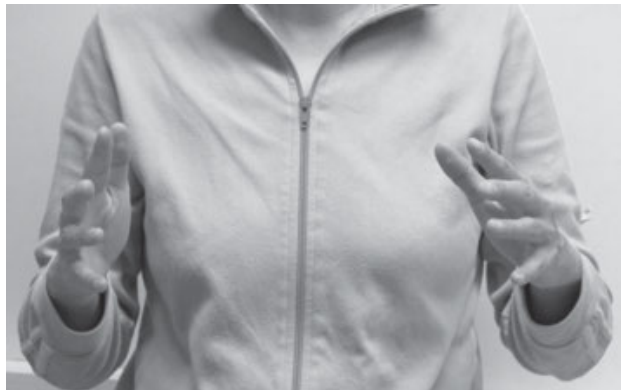

Figure 8. MANY (two-handed)

These listed signs are used as adjectives or predicates to describe nominal signs. They are often used to show different quantities, mass or levels of something. Alternatively, when explaining the intensity of colour or the degree of pain, for example, the index finger is used as a measurement unit. The contact point between the tip of the thumb and the index finger indicates different levels or quantities. For instance:

- The tip of the thumb touches on the tip of the index finger: A LITTLE / A BIT

- The tip of the thumb touches on the first knuckle of the index finger: LESS THAN HALF

- The tip of the thumb touches on the second knuckle of the index finger: HALF or more

- The tip of the thumb touches on the third knuckle of the index finger: VERY

This approach is used in one-on-one conversations and informal settings, it is rarely used in formal settings (except for instructional purposes). 


\section{Extent Paradigms}

The number signs in all paradigms can be replaced with an indefinite number sign (the open-5 hand wiggling fingers) to show 'a few'. If the interrogative facial expression is simultaneously combined with the open-5 hand wiggling fingers - meaning HOW-MANY - this will form a question. For example, 'what date' (see figure 9) in CSL and Hong Kong Sign Language (ref. Tang 2006:211).

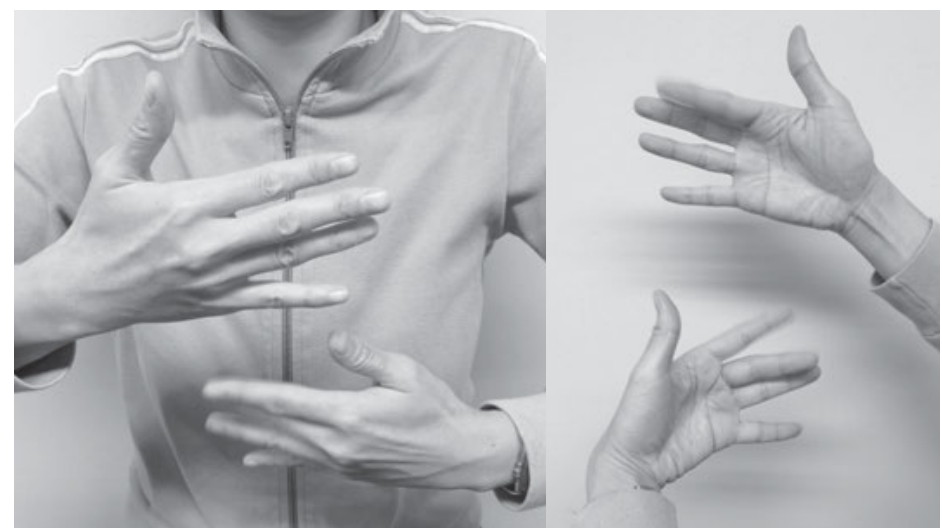

Figure 9. 'what date?'

Some number paradigms can be modified to become interrogative paradigms where the interrogatives are characterised by finger wiggling HOW-MANY are listed following Table 4.

Table 4. Extent paradigms

\begin{tabular}{llll}
\hline Paradigm & $\begin{array}{l}\text { Number } \\
\text { compounds with } \\
\text { the number 2 used } \\
\text { as an example }\end{array}$ & $\begin{array}{l}\text { Interrogative } \\
\text { signs with } \\
\text { Wh-sign (finger } \\
\text { wiggle) }\end{array}$ & $\begin{array}{l}\text { Indefinite number } \\
\text { compounds with } \\
\text { "several" }\end{array}$ \\
\hline Age & 2-years-old & $\begin{array}{l}\text { how-many-age } \\
\text { 'how old' }\end{array}$ & No \\
Person & 2-person & how-many-person & Yes \\
Row & 2-row & how-many-row & No \\
Size & size-2 & how-many-size & $\begin{array}{l}\text { Yes }+ \text { 个 } \\
\text { (borrowing } \\
\text { Chinese classifier) }\end{array}$
\end{tabular}




\begin{tabular}{|c|c|c|c|}
\hline Deaf & $2^{\text {nd }}$-deaf-school & $\begin{array}{l}\text { what-number-of- } \\
\text { deaf-schools }\end{array}$ & No \\
\hline Time & 2 o' clock & what-time & No \\
\hline Date & $2^{\text {nd }} \mathrm{Feb}$ & what-date & No \\
\hline Day / One-day & 2-day & how-many-day & Yes \\
\hline Days of the week & Tuesday & $\begin{array}{l}\text { what-day-of-the- } \\
\text { week }\end{array}$ & No \\
\hline One-month & 2-months & how-many-month & $\begin{array}{l}\text { Yes }+ \text { 个 } \\
\text { (borrowing } \\
\text { Chinese classifier) }\end{array}$ \\
\hline $\begin{array}{l}\text { Months of the } \\
\text { year }\end{array}$ & February & $\begin{array}{l}\text { what-month-of- } \\
\text { the-year }\end{array}$ & No \\
\hline Yes /One-year & 2-year & how-many-year & Yes \\
\hline Hour/ One-hour & 2-hour & how-many-hour & Yes \\
\hline $\begin{array}{l}\text { Hundred / One- } \\
\text { hundred }\end{array}$ & 200 & $\begin{array}{l}\text { how-many- } \\
\text { hundred }\end{array}$ & Yes \\
\hline $\begin{array}{l}\text { Thousand / One- } \\
\text { thousand }\end{array}$ & 2000 & $\begin{array}{l}\text { how-many- } \\
\text { thousand }\end{array}$ & Yes \\
\hline Grade-one & GRADE-TWO & what-grade & No \\
\hline $\begin{array}{l}\text { The First (place in } \\
\text { the line or on list) }\end{array}$ & $2^{\text {nd }}$ & $\begin{array}{l}\text { how-many-in- } \\
\text { order }\end{array}$ & Yes \\
\hline
\end{tabular}

The table 4 above shows that simultaneous morphology in number signs and compounding patterns are productive and flexible in the CSL lexicon.

\section{Conclusion}

This study shows that the one-handed number signs and quantifiers offer a great advantage to CSL phonology and morphology, as they enable a high level of flexibility of articulation and possibilities for incorporation. The comparative/contrastive analysis of the Beijing and Shanghai variation in number signs and compounding patterns demonstrates that the Beijing variation has a clearer articulation path and morphological process, and is preferential to a large number of CSL users. For example, the number sign TEN in the Beijing variety has a clear and distinct handshape and location but 
the Shanghai variant is almost homonymous with the other signs, hence the preference for the Beijing variant. This variance is more in keeping with a standard variety and as it has been adopted for the CSL dictionary, may develop as a standard variance that sees further geographical distribution in future years.

\section{References}

Fischer, Susan D. \& Qunhu Gong. 2010. Variation in East Asian sign language structures. In D. Brentari (ed.) Sign Languages (Cambridge Language Survey series). pp. 502-521. Cambridge: Cambridge University Press.

Ktejik, Mish. 2013. Numeral Incorporation in Japanese Sign Language. Sign Language Studies, 13, pp. 186-209.

Liddell, Scott K. 1996. Numeral Incorporating Roots and Non-Incorporating Prefixes in American Sign Language. Sign Language Studies, 92, pp. 201-23.

Tang, Gladys. 2006. Questions and Negation in Hong Kong Sign Language. In Zeshan, Ulrike (ed.) Sign Language Typology: Interrogatives and Negation. Nijime, Netherlands: Ishara Press.

Yang, Jun Hui \& Susan D. Fischer. 2002. Expressing negation in Chinese Sign Language. Sign Language \& Linguistics, 5 (2), pp. 167-202.

Zeshan, Ulrike. 2000. Sign Language in Indo-Pakistan: A Description of a Signed Language. Philadelphia: Benjamins. 